\title{
EVIDENCE FOR ECOLOGICAL CHARACTER DISPLACEMENT IN WESTERN AMERICAN CATOSTOMID FISHES
}

\author{
A. E. Dunham, G. R. Smith, and J. N. Taylor \\ Museum of Zoology, University of Michigan, Ann Arbor, Michigan 48109
}

Received May 12; 1978. Revised December 18, 1978

Much of recent ecological theory rests on the assumption that the primary factor responsible for the organization of natural communities, particularly of animals, is interspecific competition (e.g., MacArthur, 1972; Schoener, 1975). The validity of this assumption depends almost exclusively on inference drawn from observational evidence of two types. Morphological changes in the form of ecological character displacement (Brown and Wilson, 1959; Grant, 1972) and niche shifts correlated with geographic variation in the number or density of closely related species are generally considered the strongest available evidence for the importance of interspecific competition (MacArthur, 1972; Cody, 1974; Schoener, 1974, 1975).

Grant (1972, 1975) defines ecological character displacement to be "the process by which a morphological character state of a species changes under natural selection arising from the presence, in the same environment, of one or more species similar to it ecologically ...." By this definition Grant would include both character convergence and divergence but would exclude cases of changes in character state due to the related process of character release.

It seems clear that the interspecific interaction implicit in Grant's $(1972,1975)$ definition of ecological character displacement is competition. Furthermore, this causal relationship must be demonstrated if ecological character displacement is to be used as observational evidence for the occurrence of interspecific competition. Therefore, we define competitive character displacement to be a change of character state in a population that is due to natural selection arising as a result of com- petition with individuals of another population in the same environment. The characters may be morphological, ecological, behavioral, or physiological and the change may be either divergent or convergent. By divergent competitive character displacement we mean that a character state of a population in ecological sympatry (=syntopy, Rivas, 1964) exhibits greater difference than is the case when allopatric populations are contrasted, and that this effect can be attributed to sympatry. If the contrast of allopatric and sympatric populations reveals that the character states of the two populations are more similar in areas of sympatry than in areas of allopatry and if this effect can be attributed to competition, then the situation is one of convergent character displacement. Ecological theory predicts those situations in which convergent or divergent displacement would be expected (MacArthur and Levins, 1964, 1967; MacArthur and Wilson, 1967; Schoener, 1969a, 1969b, 1970; MacArthur, 1972). In all of these models the selection responsible for the character state change or niche shift arises as a result of interspecific competition.

Grant (1972) in his critical review of the evidence for ecological character displacement, concluded that "the evidence for the ecological aspect of morphological character displacement is weak" and that "the detection of character displacement in its ecological aspect, particularly in mainland regions, will require a level of detail that has so far not been produced in a single study."

The weakness of the available evidence for competitive character displacement lies in the difficulty of establishing unambiguously that the character state of 

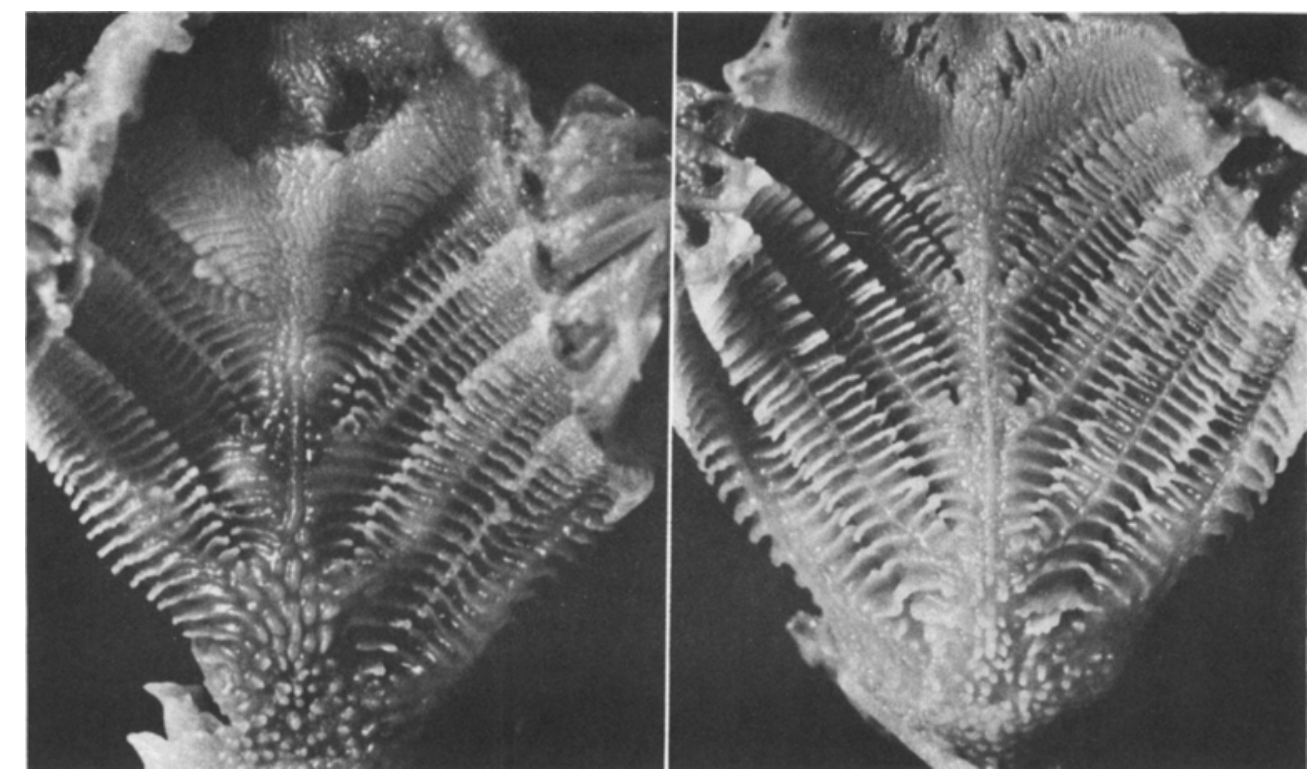

FIG. 1. Ventral portion of pharyngeal sieve of C. platyrhynchus (left), $126 \mathrm{~mm}$ standard length (first right arch removed), and $C$. discobolus (right), $123 \mathrm{~mm} \mathrm{S.L.} \mathrm{Values} \mathrm{in} \mathrm{this} \mathrm{study} \mathrm{refer} \mathrm{to} \mathrm{the} \mathrm{number} \mathrm{of}$ rakers in the anterior row on the first (anterior) arch.

one population in sympatry is really influenced by the presence of a coexisting, ecologically similar population. Factors other than competitive interaction with an ecologically similar species may affect the character state exhibited by a given population. Therefore, the demonstration of competitive character displacement requires that the effect (if any) of sympatry with an ecologically similar population be quantified and separated from all other factors which affect the phenotypic manifestation of the character of interest. The requirement is one of partitioning the variance observed in the character of interest into that component which is due to sympatry and that attributable to all other sources. It is reasonable to infer that a shift in character state is due to competitive character displacement only if there is a significant component of variation which is accounted for by sympatry with an ecologically similar population, after the variation attributable to other sources is accounted for.

Grant (1972) effectively identified this as the essential nature of the problem.
However, in his (1975) reexamination of the classical case of morphological displacement in the rock nuthatches, Sitta tephronota and $S$. neumayer, he was unable to carry out this partitioning. Nonetheless, his analysis revealed no evidence for competitive character displacement in either body size or bill size. Since Grant's (1972) review, several papers have appeared which purport to demonstrate ecological character displacement (Huey et al., 1974; Huey and Pianka, 1974; Berry, 1975; Fenchel, 1975; Kellog, 1975; Husar, 1976). None of these studies partitions the variation into a component explained by sympatry and a component explained by other factors.

In this study we critically examine the evidence for competitive character displacement which has accumulated since reviews by Grant (1972) and Nursall (1974) and present an analytical paradigm for testing for the existence of competitive character displacement in an example involving the mountain suckers of the family Catostomidae.

Patterns of variation in gill raker num- 


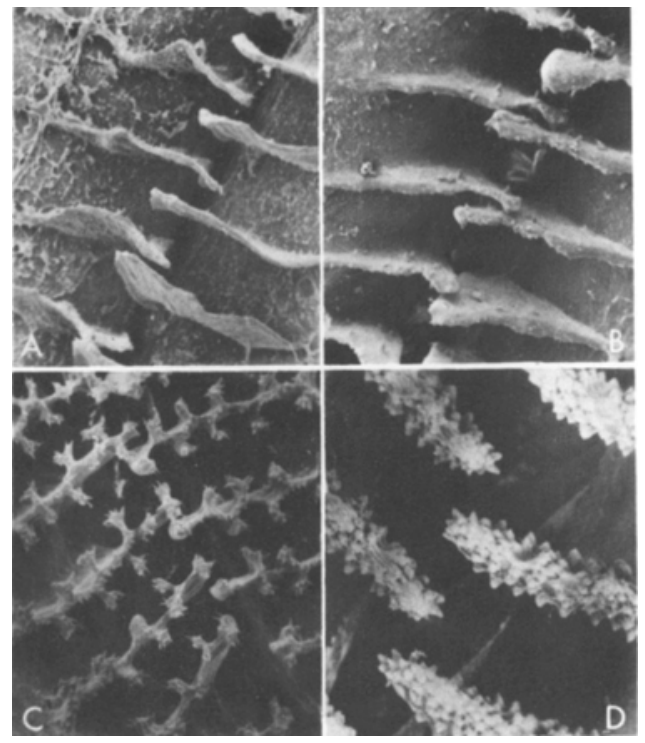

Frg. 2. Scanning electron micrographs of gill rakers on the first and second gill arches of (A) $\mathrm{Ca}$ tostomus discobolus (123 mm S.L.), (B) C. platyrhynchus (126 mm S.L.), (C) C. columbianus $(126$ $\mathrm{mm}$ S.L.), (D) C. commersoni (126 mm S.L.). Magnification $50 \times$.

bers in the mountain sucker Catostomus (Pantosteus) platyrhynchus and the bluehead sucker $C$. discobolus were offered as an example of character displacement by Smith (1966). Number of gill rakers (which increases ontogenetically) was regressed on length of the fish; comparison of overlap between sympatric populations of the two species revealed greater divergence than that observed in comparisons of allopatric populations (Smith, 1966, Fig. 6). Reduction in morphological overlap in areas of sympatry was presumed to result from competitive reduction in available food resources in an intermediate area of the resource distribution. Dimensions of this resource distribution must be defined in part by food particle size. Suckers have nine rows of gill rakers distributed on five pairs of gill arches. The rows interdigitate to form a sieve (Fig. 1) that separates particles to be ingested from those that are discarded. Individual rakers have rows of small spines (Fig. 2); manipulation of the rows in response to taste cues forms an active, variable-meshed sieve for particle sorting. The spacing is graded, being wider anteriorly and narrower posteriorly (Fig. 1). When feeding, suckers ingest both substrate and food particles, actively exercise head and branchial musculature, then eject sand and detritus from the opercular openings and (or) mouth while retaining and swallowing food items.

Natural selection for optimal spacing of rakers is probably affected by size-frequency distributions of available food particles and of detrital substrate particles that must be processed and cleared from the rakers. The general relationship between gill raker number and food particle size is well known but not yet functionally analyzed. Species of minnows and suckers that eat fine, particulate organic matter, diatoms, and minute benthos, have more numerous, closely spaced rakers than related forms that eat larger food items.

Zoogeographic considerations (Smith, 1966) suggest that $C$. discobolus differentiated in the Colorado drainage and is a rather late (Pleistocene) immigrant to adjacent areas in the Snake and Bonneville systems, while the opposite relationship holds for $C$. platyrhynchus, although the latter also occurs in several other drainages (Fig. 3). In general, $C$. discobolus inhabits larger streams dominated by sandy substrate (in the Colorado) or coarser rubble (in the Bonneville-Snake). By contrast, $C$. platyrhynchus is generally found in smaller streams over rubble substrate, and (in areas of sympatry) occupies habitats upstream from typical $C$. discobolus situations.

Specimens of $C$. discobolus have more gill rakers than equivalent-sized $C$. platyrhynchus, with little overlap between populations (Smith, 1966, Fig. 6). Stomach contents found in individuals of each species include fine particulate organic matter, filamentous algae, diatoms, midge larvae (Tendipedidae), other small aquatic insects, and silt or fine sand. Diatoms, larvae, and sand occasionally occur in abundance. The inorganic detritus might have carried attached food or might be unde- 


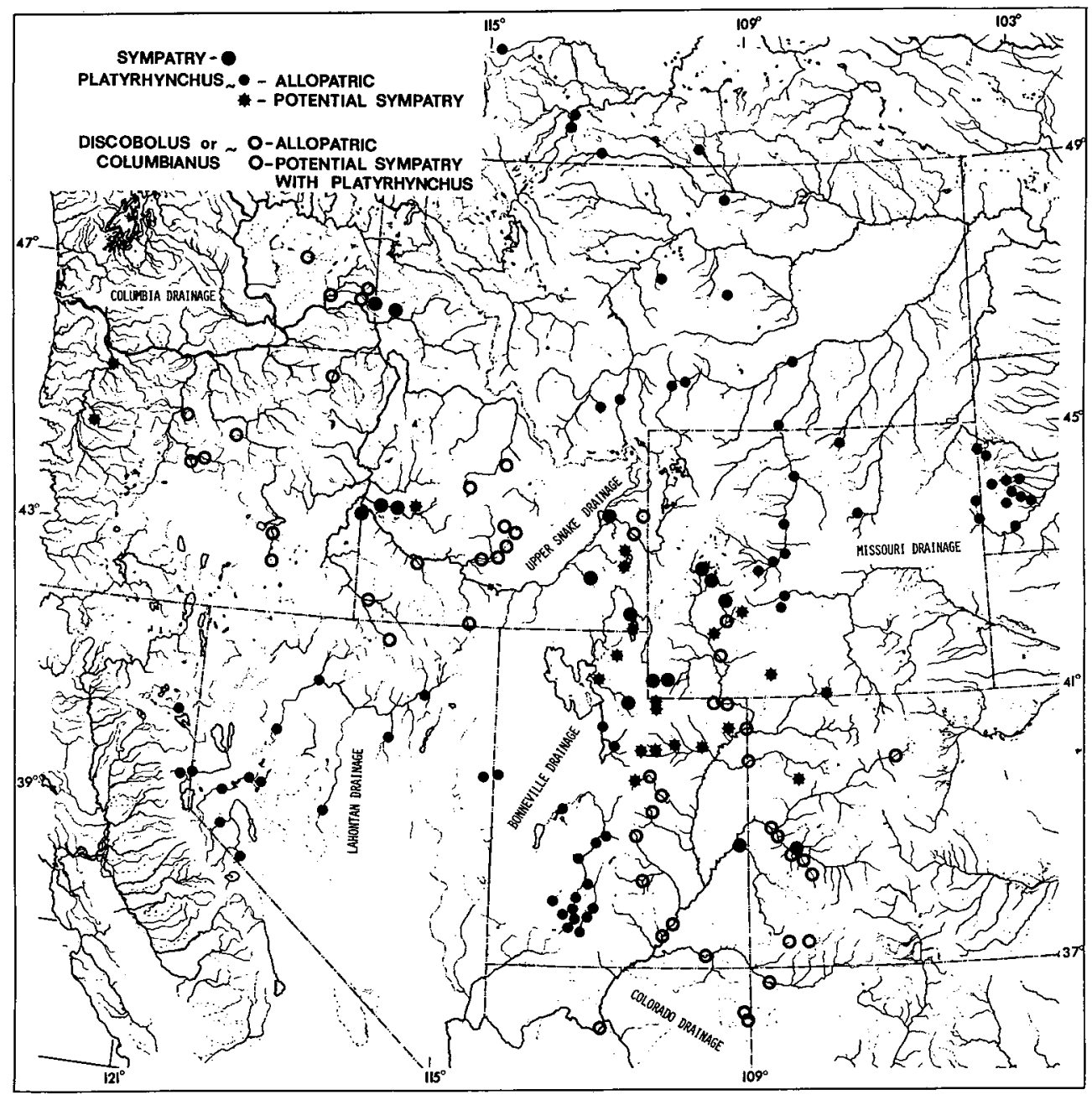

FIG. 3. Distribution of Catostomus platyrhynchus, discobolus, and columbianus samples analyzed in this study. Compare with Table 2.

sirable matter that was not rejected by the rakers. Although qualitative examination suggests that smaller food items are found in smaller individuals and in $C$. discobol$u s$, quantification of such a relationship has not been practical because of the flocculent, amorphous nature of most gut contents.

Combining information about distribution, habitat, and gill-raker function in suckers suggests several predictions regarding effects of competition and environmental variables on gill-raker number:

1) Fishes taking smaller food items should be able to feed more efficiently if they have smaller spaces between rakers. Raker numbers increase with growth to allow more spaces (enlargement of the sieve) without undue enlargement of the spaces. In areas of sympatry, reduction of modal food resources by competition should shift the optima of food size availability apart. Adaptive responses in gillraker number would be a shift upward for C. discobolus and downward for C. platyrhynchus.

2) Fishes that live over coarser substrate might have coarser spacing of gill rakers 

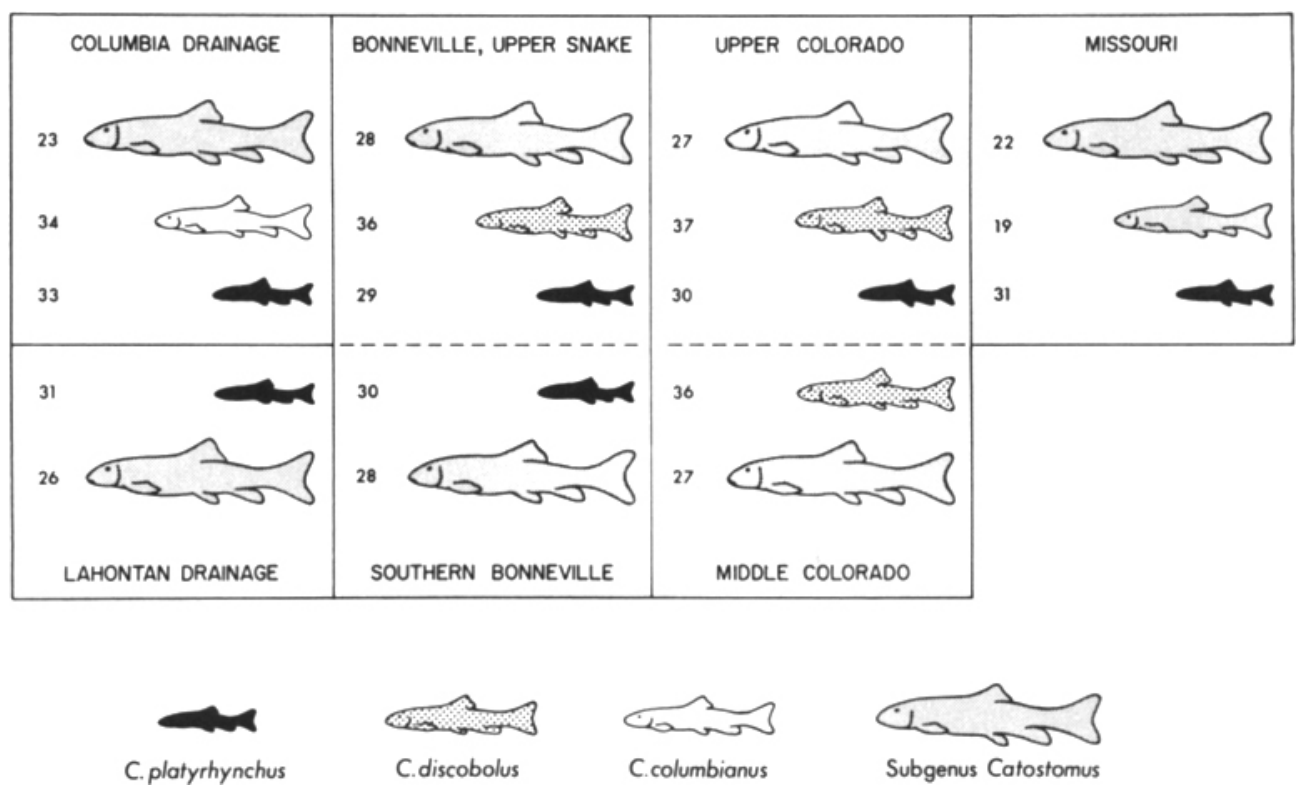

FIG. 4. Diagrammatic outline of relative size, modal number of gill rakers, and association by drainage of fishes analyzed in this study.

in response to the problem of fouling and cleaning of the sieve. Coarser substrate is found in upstream, high-gradient, highvelocity areas of streams. Therefore, number of gill rakers might be negatively correlated with elevation, gradient, and perhaps discharge, if all other factors were constant.

3) Because meristic characters (e.g., numbers of gill rakers, vertebrae, scale rows, and fin rays) are affected by temperature of development (Hubbs, 1926; Taning, 1952; Barlow, 1961; Fowler, 1970), generally in a negative direction, such measures are expected to increase with latitude and elevation.

4) Mountain suckers occur with other suckers of the genus Catostomus at nearly all localities. The similarity in morphology and microhabitat is not as great and the competition should not be as intense. Table 1 and Figure 4 show gill-raker numbers in the species in this study. All members of the subgenus Catostomus (see Fig. 2) in the study have lower numbers than C. platyrhynchus and C. discobolus and prefer larger, slower habitats. Catostomus columbianus, which replaces $C$. discobol$u s$ as a potential competitor of $C$. platyrhynchus in the Columbia drainage below the falls of the Snake, has high gill-raker counts like $C$. discobolus. Competition with Catostomus (s.s.) should displace gill-raker numbers upward in $C$. platyrhynchus, C. discobolus and C. columbianus for the reasons given in (1) above.

5) Displacement effects should be predictably different in different ecological settings. Maximum competitive effect should occur where $C$. discobolus and $C$. platyrhynchus exist in the same habitats, mutually reducing available food. Selection-mediated displacement to nearby allotopic habitats is a possible result of the competition, as is local elimination of one of the competitors. Outside their area of sympatry, $C$. platyrhynchus and $C$. discobolus should be relatively more affected by other species and environmental variables.

Displacement might be expected to differ in the Bonneville and Colorado drainage systems because sympatry has come about as a result of immigration of $C$. dis- 
TABLE 1. Numbers of gill rakers and vertebrae. (C.) indicates the subgenus Catostomus; * = data are for adults larger than about $250 \mathrm{~mm}$ standard length. (P.) indicates the subgenus Pantosteus.

\begin{tabular}{|c|c|c|c|}
\hline Species & Drainage & Gill rakers & Vertebrae \\
\hline C. (C.) catostomus & Missouri & $19-24 *$ & $41-44$ \\
\hline C. (C.) commersoni & Missouri & $22-25^{*}$ & $42-44$ \\
\hline C. (C.) macrocheilus & Columbia & $23-29 *$ & $44-46$ \\
\hline C. (C.) ardens & Bonneville-upper Snake & $28-31^{*}$ & $43-46$ \\
\hline C. (C.) latipinnis & Colorado & $22-29 *$ & $43-46$ \\
\hline C. (C.) tahoensis & Lahontan & $26-28 *$ & $40-42$ \\
\hline C. $(P$.$) columbianus$ & Columbia & $24-42$ & $39-46$ \\
\hline C. (P.) platyrhynchus & $\begin{array}{l}\text { Great Basin, Columbia, } \\
\text { Missouri, Saskatchewan, } \\
\text { Colorado }\end{array}$ & $23-37$ & $38-44$ \\
\hline C. $(P$.$) discobolus$ & $\begin{array}{l}\text { Colorado, upper Snake, } \\
\text { northern Bonneville }\end{array}$ & $26-44$ & $41-46$ \\
\hline
\end{tabular}

cobolus from the Colorado to the Bonneville (including the upper Snake River) and $C$. platyrhynchus from the Bonneville to the Colorado, probably in the Pleistocene. In addition, the sandy-substrate portion of $C$. discobolus' habitat spectrum is uncommon in the Bonneville-upper Snake system, reducing the opportunity for spatial segregation. The consequence of this reciprocal immigration, which extends only into the north end of each drainage system, should be an effect on the northern populations relative to the southern populations of each species. The immigrant populations would be expected to be displaced relative to allopatric southern populations of their own species. However, because of the relative absence of sand-substrate habitat in the Bonneville, immigrant populations of $C$. discobolus there should experience a greater competitive effect.

6) General observations of geographic variation suggest that other characteristics of mountain suckers may also show character displacement. The number of postWeberian vertebrae, which is independent of growth and shows no within-population correlation with gill raker number, shows a pattern roughly similar to that of gill raker number (Fig. 4). In addition, general body size, though difficult to analyze, shows similar trends, $C$. discobolus having a maximum length about twice that of C. platyrhynchus (Fig. 4). A predictive rationale for displacement in vertebral number is difficult to construct. The number of vertebrae might be expected to vary positively with maximum adult size in the population (Lindsey, 1975). The relationship between size (length) and vertebrae should be related to the scale of segmental effects on swimming mechanics. Functional parameters are probably strength and flexibility (Gosline, 1971). Elevation, latitude and other factors related to temperature should also affect vertebral number as mentioned above for gill rakers. Theoretical considerations (Schoener, $1969 a$ ) suggest that in the case of two generalists using the same set of resources, the effect of competition on body size should be slower growth and smaller individuals of both species. The effect could be seen as concordant shifts in numbers of vertebrae. Other models are possible, however. For example, territoriality and other behavioral factors could operate to select for larger individuals of the larger species in sympatry, and intermediate sizes of both species in allopatry. In summary, the expected responses of body size and the possible correlate, vertebral number, to competition in these fishes are still not obvious, but three possible correlatesbody size, developmental temperature, and behavioral relationships-deserve testing.

In this study we examine the pattern of geographic variation in numbers of gill 
TABLE 2. Drainages, number of localities (K), sample sizes (N) for gill rakers (G.R.) and vertebrae, and competition indices for populations represented in this stuy. Abbrevations for states and provinces are initial letters of Arizona, New Mexico, Utah, Wyoming, Colorado, Nevada, Oregon, Washington, Idaho, Montana, South Dakota, Alberta, and Saskatchewan.

\begin{tabular}{|c|c|c|c|c|c|}
\hline \multirow[b]{2}{*}{ Drainage } & \multirow[b]{2}{*}{ States } & \multirow[b]{2}{*}{$\mathrm{K}$} & \multirow{2}{*}{$\frac{\mathrm{N}}{\text { G.R., vert. }}$} & \multicolumn{2}{|c|}{ Competition indices } \\
\hline & & & & I & II \\
\hline \multicolumn{6}{|l|}{ C. platyrhynchus } \\
\hline Bear & $\mathrm{U}, \mathrm{Wy}, \mathrm{I}$ & 6 & 29,17 & $1.00-1.33$ & $1.00-1.50$ \\
\hline Weber & $\mathrm{U}$ & 2 & 4,8 & $1.00-1.14$ & 1.00 \\
\hline Ogden & $\mathrm{U}$ & 1 & 4,3 & 1.00 & 1.00 \\
\hline Jordan-Provo & $\mathbf{U}$ & 2 & 37,36 & 0 & $1.00-1.21$ \\
\hline Lower Sevier & $\mathbf{U}$ & 7 & 58,46 & 0 & $1.00-1.55$ \\
\hline E. Fk. Sevier & $\mathbf{U}$ & 4 & 19,11 & 0 & 1.00 \\
\hline Upper Sevier & U & 5 & 103,96 & 0 & 1.00 \\
\hline Deep Cr.-Spring V. & $\mathrm{U}, \mathbf{N}$ & 2 & 30,23 & 0 & 1.00 \\
\hline Humboldt & $\mathbf{N}$ & 5 & 82,80 & 0 & $1.07-1.31$ \\
\hline W. Lahontan & $\mathrm{N}, \mathrm{C}$ & 9 & 83,75 & 0 & $1.22-1.95$ \\
\hline Willamette & $\mathrm{O}$ & 2 & 28,30 & 1.00 & 1.00 \\
\hline Lower Snake & Wy, O, I & 7 & 19,19 & $1.00-1.95$ & $1.00-1.42$ \\
\hline Upper Snake & I & 5 & 43,43 & $1.00-1.64$ & $1.00-1.08$ \\
\hline Cheyenne & $\mathrm{SD}, \mathrm{Wy}$ & 12 & 58,34 & 0 & $1.00-1.94$ \\
\hline Yellowstone & Wy, M & 12 & 108,85 & 0 & $1.00-1.90$ \\
\hline Sweetwater & Wy & 3 & 30,32 & 0 & $1.00-1.95$ \\
\hline Upper Missouri & $\mathrm{M}, \mathrm{Al}$ & 4 & 9,10 & 0 & $1.00-1.98$ \\
\hline Milk-Saskatchewan & $\mathrm{Al}, \mathrm{S}$ & 8 & 33,29 & 0 & $1.00-1.86$ \\
\hline Upper Green & $\mathrm{Wy}, \mathrm{U}$ & 7 & 146,123 & $1.00-1.89$ & $1.00-1.50$ \\
\hline Lower Green & $\mathrm{Wy}, \mathrm{U}, \mathrm{C}$ & 8 & 84,81 & $1.00-1.25$ & $1.00-1.72$ \\
\hline \multicolumn{6}{|l|}{ C. discobolus } \\
\hline Upper Green & Wy, U & 8 & 78,136 & $1.00-1.80$ & $1.17-1.90$ \\
\hline Lower Green & $\mathrm{U}, \mathrm{C}$ & 4 & 19,36 & 1.00 & $1.00-1.60$ \\
\hline Upper Colorado & $\mathrm{C}, \mathrm{U}$ & 11 & 52,70 & $1.00-1.29$ & $1.00-1.81$ \\
\hline Lower Colorado & $\mathrm{C}, \mathrm{U}, \mathrm{Ar}, \mathrm{NM}$ & 11 & 124,183 & 0 & $1.00-1.87$ \\
\hline Bear-Weber & $\mathrm{Wy}, \mathrm{U}, \mathrm{I}$ & 5 & 38,50 & $1.00-1.86$ & $1.00-1.60$ \\
\hline Snake & I & 4 & 51,60 & $1.00-1.64$ & $1.00-1.50$ \\
\hline \multicolumn{6}{|l|}{ C. columbianus hubbsi } \\
\hline Wood & $\mathbf{I}$ & 5 & 42,44 & 0 & 0 \\
\hline \multicolumn{6}{|c|}{ C. columbianus columbianus } \\
\hline Lower Snake & $\mathrm{I}, \mathrm{N}, \mathrm{O}$ & 15 & 119,120 & $1.00-1.50$ & $1.00-1.80$ \\
\hline Palouse & $\mathrm{Wa}$ & 4 & 43,51 & $1.00-1.02$ & $1.00-1.50$ \\
\hline Columbia & $\mathrm{O}, \mathrm{Wa}$ & 5 & 64,82 & $0-1.00$ & $1.00-1.84$ \\
\hline
\end{tabular}

rakers and vertebrae to determine whether the presence of potential competitors can be shown unequivocally to be associated with character displacement. The functional mechanism whereby competition might influence selective change in numbers of gill rakers is discussed, but its analysis is deferred to later study. It is intended that the description of the relationship between variation and environmental variables will help formulate the direction of subsequent ecological and functional studies.

\section{Materials}

Data were assembled on 2,049 specimens from 182 populations representing Catostomus (Pantosteus) discobolus (Colorado and northern Bonneville drainages), C. platyrhynchus (widespread except southern Colorado drainage), and $C$. Columbianus (Columbia drainage) distributed as in Table 2 and Figure 3. Counts and measurements include size, gill raker numbers, and vertebral numbers (Smith, 1966). Because the number of gill rakers 
TABLE 3. Sources of environmental data used in regression analyses.

\begin{tabular}{|c|c|}
\hline Environmental variable & Source \\
\hline $\begin{array}{l}\text { Competition index } \mathrm{I} \\
\quad \text { (C. discobolus } \times \text { C. platyrhynchus })\end{array}$ & $\begin{aligned}=1 & +\frac{\text { number of competitors in sample }}{\text { total of both species in sample }} \\
& \text { (but } 0 \text { if the competing species does not occur in the } \\
& \text { drainage) }\end{aligned}$ \\
\hline $\begin{array}{l}\text { Competition index II } \\
\text { (Pantosteus spp. } \times \\
\text { Catostomus [s.s.] spp.) }\end{array}$ & $\begin{array}{c}=1+\frac{\text { number of individuals of Catostomus (s.s.) in sample }}{\text { number of Catostomus }+ \text { number of } C . \text { platyrhyn- }} \\
\text { chus or C. discobolus } \\
\text { (but } 0 \text { if Catostomus (s.s.) does not exist in the drainage) }\end{array}$ \\
\hline Elevation & $\begin{array}{l}\text { topographic maps of U.S. and Canadian Geological Surveys } \\
\text { and Gazeteer of Utah localities and altitudes }{ }^{1}\end{array}$ \\
\hline Gradient & $\begin{array}{l}\text { topographic maps. Measured as distance: } 200 \mathrm{ft} \text { change at } \\
\text { sample locality }\end{array}$ \\
\hline Mean discharge & 50 year data from U.S.G.S. Water Supply Papers ${ }^{2}$ \\
\hline Minimum discharge & 50 year data from U.S.G.S. Water Supply Papers ${ }^{2}$ \\
\hline Latitude, longitude & topographic maps \\
\hline
\end{tabular}

1 Division of Biology, University of Utah, Salt Lake City, 1952.

${ }^{2}$ U.S. Government Printing Office.

Sample data from Museum of Zoology, The University of Michigan, and the Institute of Fisheries, University of British Columbia.

follows a curvilinear relationship to length of the fish, analyses of gill rakers were based on specimens between 25 and 125 $\mathrm{mm}$ in standard length-a subsample showing a straight-line relationship with almost normally distributed residuals from regression when plotted as log number of gill rakers against log standard length. The data set including all sizes was also analyzed for comparison.

Data on environmental variables were assembled from museum records, topographic maps, and records from stream gauging stations (Table 3 ). Two indices of competition are used and each has two parts. Competition index I $(C$. discobolus $\times C$. platyrhynchus) includes a code value for long-term potential for competitive effect (a value of 0 for allopatry, 1 for potential sympatry) plus an additional estimate of the intensity of local competition among sympatric populations in the form of the ratio of the number of individuals of the competing species to the total number of both species in the sample (e.g., $1.0=$ sympatry, but no competitors actually collected; $1.5=$ equal numbers collected). It is an estimate of both long- term and immediate potential competition for each sample. The estimate of potential competition from suckers in the subgenus Catostomus in each sample was computed from collection data in the same way and constitutes index II. The competition indices vary between 0 and 1.98 (Table 2).

The other variables-elevation, gradient, mean and minimum discharge, latitude, and longitude - are included in the study because of their potential relationships to habitat, current, substrate, food resources, developmental temperature, and geographic variation in general. Considerable correlation among these effects is to be expected. Favorable habitat in these fishes is determined by interaction of temperature, current velocity, and substrate, which are, in turn, affected by elevation, gradient, and discharge. Temperature is also a function of latitude. It is assumed that other factors affecting geographic variation, clines, gene flow, and divergence, are superficially summarized by the spatial coordinates, latitude and longitude.

Populations are separated into zoogeographic units for purposes of comparison. 
The Columbia drainage includes ( $C$. platyrhynchus and $C$. columbianus) populations in the Snake River below Twin Falls. The upper Snake River (C. platyrhynchus and $C$. discobolus) is included in the Bonneville zoogeographic unit because of the similarity of these faunas, resulting from the Pleistocene Bonneville spillover into the upper Snake (Smith, 1978). The area of sympatry between $C$. discobolus and $C$. platyrhynchus is defined to include the Bonneville from the Weber River northward, the upper Snake, the northern Green River drainage south to the Price and White River drainages, and the upper Colorado drainage in Colorado and Utah (Fig. 3). It is possible that $C$. platyrhynchus is not really an inhabitant of the upper Colorado drainage in Colorado (Smith, 1966, p. 70), and in any case it must be extremely rare in historic times; therefore the analyses were carried out twice to test the effects on the general model of considering that drainage to contain only allopatric $C$. discobolus in contrast to sympatric populations. In the Wood River system, tributary to the lower Snake River in the Columbia drainage unit, there exists a form of $C$. columbianus that is isolated and allopatric above barrier falls. This form, C. columbianus hubbsi, is distinctive in the possession of low gill raker numbers like $C$. platyrhynchus. Analyses were carried out with and without this population present in the model in order to determine whether evidence for character displacement exists either way.

We tested the null hypothesis that there has been no significant effect of sympatry with potential competitors in the same subgenus (Pantosteus) and with potential competitors in the subgenus Catostomus, using both forward and backward stepwise, multiple linear regression analysis (Draper and Smith, 1966). Separate analyses were run for each species using the natural logarithms of the number of anterior gill rakers and the number of vertebrae as dependent variables and the array of independent variables previously enumerated (Table 3 ).

The stepwise procedure admits inde- pendent variables into the regression model one at a time according to the partial correlation with the dependent variable, given the effects of previously admitted independent variables. In these analyses the "best" regression model was taken to be that which included only statistically significant partial regression coefficients and accounted for the greatest proportion of variance in the dependent variable.

Separate regression models were computed for each species (C. platyrhynchus, $C$. discobolus, and C. columbianus). For comparison, the samples of each species were then partitioned into those representing sympatry with a potential subgeneric competitor and those representing allopatry, and new regression models computed. In addition, separate regression models were computed for $C$. platyrhynchus and $C$. discobolus populations from the Colorado and Bonneville systems because of our interest in the historical interaction in these drainages.

Prior to carrying out these analyses, we made predictions as to the effects of the variables in the array of independent variables on the dependent variables. Evidence for ecological character displacement was taken to be a statistically significant partial regression coefficient for either of the competition variables (Comp. I, Comp. II).

It is possible that the indices of competition are inadequate and that in the area of sympatry, certain values of variables usually associated with presence of the competing species (certain gradient, elevation, or discharge values) are better estimators of long-term competitive effects than the abundance of the competitor in individual collections. If so, these variables might show higher correlations than the competition index with the displacement of a character. The test of this idea is comparison of separate stepwise multiple linear regression models for allopatric and sympatric population groups. A displacement response to an environmental variable could occur only in sympatric but not allopatric situations if it were actually due to competition, but the correlation 
would exist in allopatry, sympatry, and overall if it were a primary effect independent of competition. Similarly, collinearity among environmental variables and a competition index may be resolved by the stepwise algorithm by elimination of the competition index, even if it were the primary cause of variation. Again, the test of this phenomenon is comparison of allopatric and sympatric population groups. Variables significant in allopatry would not be reflecting hidden competition effects.

For example, since northern populations of $C$. discobolus are all in the region of sympatry and southern populations are in the region of allopatry, any effect of competition on gill raker number should be highly correlated with latitude. If numbers of gill rakers were significantly correlated with latitude within the area of allopatry, however, competition could not be claimed to be the cause of the variation in sympatric areas without strong independent evidence. If, on the other hand, numbers of gill rakers were highly correlated with latitude (and competition) in the individual drainages but not within the allopatric populations, then competition would be the most likely cause, and comparison of the stepwise regression models should reveal it. However, it will always be the case that an untested variable might be causing correlated variation in occurrence of sympatry and numbers of gill rakers.

\section{RESULTS \\ Gill Rakers}

Great Basin, upper Snake, Colorado, and Missouri drainages.-Preliminary observations and predictions regarding character displacement are largely confirmed by the stepwise multiple regression analyses. Table 4 shows the resulting partial correlations and their significance for various comparisons, based on specimens $25-125 \mathrm{~mm}$ in standard length in all drainages except the Columbia. Variation in the number of gill rakers in $C$. platyrhynchus is significantly correlated with

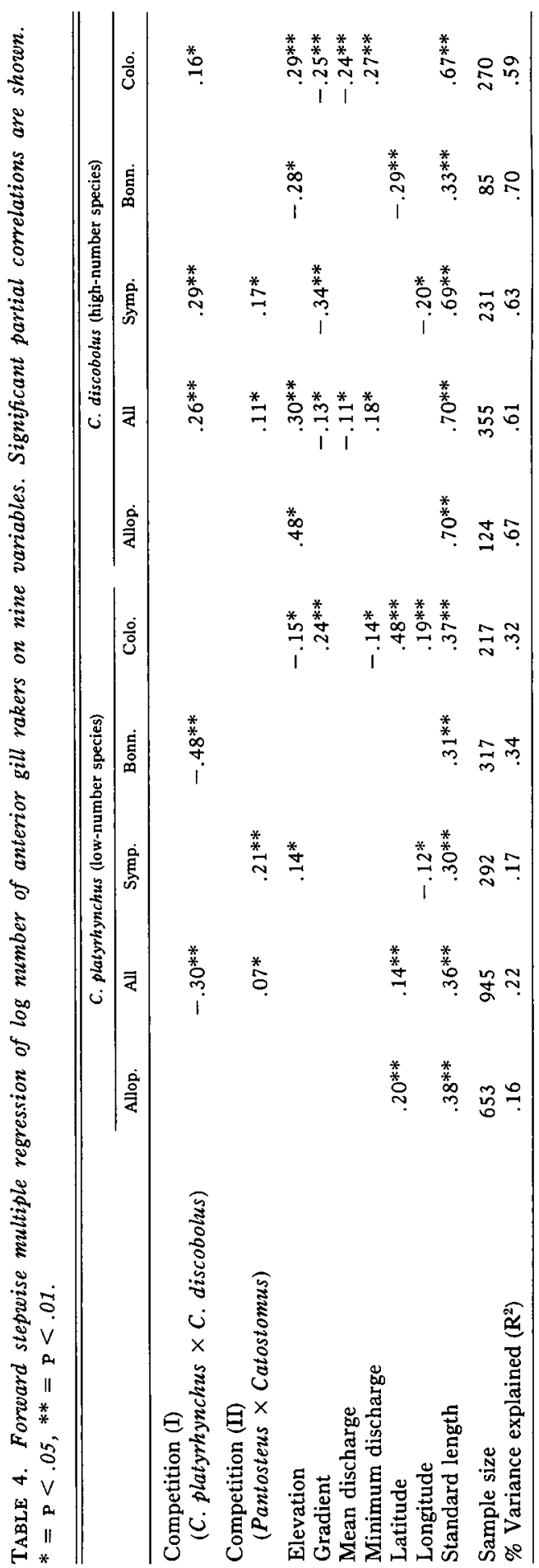


the index (I) of competition with $C$. discobolus over the entire range and in the Bonneville Basin. The comparable correlation in $C$. discobolus is significant overall and in the Colorado drainage. The directions of displacement are as predicted. In the area of sympatry, where the competition (I) index is restricted to variation in relative abundance in the samples, $C$. discobolus shows a significant response to competitor abundance, but $C$. platyrhynchus does not. Essentially identical results were obtained with the backwards stepwise regression model (results not shown), indicating a stable model.

In the overall model, $C$. platyrhynchus has fewer gill rakers in the presence of $C$. discobolus, in the south, and in the absence of Catostomus (s.s.) spp. By contrast, $C$. discobolus has more gill rakers in the presence of $C$. platyrhynchus, in the presence of Catostomus, at high elevations, in low gradients, and in small, stable streams.

In sympatry with each other, both species respond to the abundance of other species of Catostomus with a stronger tendency to increase the number of gill rakers. In addition, sympatric $C$. platyrhynchus have fewer gill rakers at low elevations and in the west (Bonneville). In sympatric $C$. discobolus, there is a significant gill raker increase in low gradients and in the east.

In allopatry (with respect to each other) C. discobolus and C. platyrhynchus show few correlations between the independent variables and variation in gill-raker number. Elevation has a positive, highly significant effect on $C$. discobolus and latitude is positively correlated with variation in $C$. platyrhynchus. The index of competition with Catostomus is insignificant in both cases.

In the Bonneville Basin and upper Snake River, $C$. discobolus is limited to the area of sympatry and consequently has limited variation in the competition (I) index (1.0-1.86), and shows no significant competitive effect. The equivalent situation exists for C. platyrhynchus in the Colorado drainage.
In both species the correlation between number of gill rakers and environmental variables is extensive in the Colorado drainage and weak or absent in the Bonneville. The direction of the effect is opposite in the two species for all significant variables except longitude-both species show a trend toward more gill rakers in the western Colorado drainage. The trend in the Colorado basin is toward fewer gill rakers in C. platyrhynchus at high elevation, low gradients, stable streams (high minimum discharge), and in the south; $C$. discobolus shows more gill rakers at high elevations, low gradients, high minimum discharge, in small streams, and in the presence of $C$. platyrhynchus. In the Bonneville Basin, $C$. discobolus has more gill rakers at low elevations and in the south.

Considering the variables in terms of their own profiles in Table 4, it can be seen that the effect of elevation is most important, especially on $C$. discobolus and in the Colorado drainage. Similarly, effects of the three fluvial variables are especially important on $C$. discobolus and in the Colorado. Effects of co-occurrence with species of Catostomus (s.s.) are greatest in the presence of sympatric Pantosteus. Effects on sympatric Pantosteus are most easily demonstrated in comparisons that include some allopatric populations. In $C$. platyrhynchus, latitude shows the trends predicted by the relationship between gill rakers and temperature. The variables chosen explain about two-thirds of the variation in gill rakers in $C$. discobolus, but only a third or less in $C$. platyrhynchus. The relationship between number of gill rakers and size is generally consistent and is usually much stronger in C. discobolus.

Columbia drainage.-In the Columbia drainage below Twin Falls on the Snake River, Catostomus platyrhynchus is sympatric with Catostomus (Pantosteus) columbiamus and $C .(C$.$) macrocheilus. The$ presence of $C$. columbianus in these habitats eliminates the usefulness of considering these populations of $C$. platyrhynchus as allopatric with regard to $C$. 
TABLE 5. Comparison of effects on number of gill rakers and vertebrae in $\mathrm{C}$. platyrhynchus and $\mathrm{C}$. columbianus. Significant partial correlations are shown. ${ }^{*}=\mathbf{P}<.05, * *=\mathbf{P}<.01$.

\begin{tabular}{|c|c|c|c|c|c|c|}
\hline & \multicolumn{2}{|c|}{ C. platyrhynchus } & \multicolumn{4}{|c|}{ C. columbiantus } \\
\hline & \multirow[b]{2}{*}{$\begin{array}{c}\text { Gill } \\
\text { rakers }\end{array}$} & \multirow[b]{2}{*}{ Vertebrae } & \multicolumn{2}{|c|}{ Gill rakers } & \multicolumn{2}{|c|}{ Vertebrae } \\
\hline & & & $\begin{array}{l}\text { C. col } \\
\text { umbianus } \\
+ \text { hubbsi }\end{array}$ & $\begin{array}{l}\text { C. col } \\
\text { umbianus } \\
\text { alone }\end{array}$ & $\begin{array}{l}\text { C. col- } \\
\text { umbianus } \\
+ \text { hubbsi }\end{array}$ & $\begin{array}{l}\text { C. col } \\
\text { umbianus } \\
\text { alone }\end{array}$ \\
\hline $\begin{array}{l}\text { Competition index }(\mathrm{I}) \\
\quad(\text { C. columbianus } \times \text { C. platyrhynchus })\end{array}$ & $-.31^{*}$ & & $.16^{* *}$ & & $.17^{* *}$ & .11 (N.S.) \\
\hline $\begin{array}{l}\text { Competition index }(\mathrm{II}) \\
\quad(\text { Catostomus } \times \text { Pantosteus })\end{array}$ & & & $.40^{* *}$ & & & $-.23 * *$ \\
\hline $\begin{array}{l}\text { Elevation } \\
\text { Gradient }\end{array}$ & $-.35^{*}$ & $-.38 * *$ & $.39 * *$ & & $-.18^{* *}$ & $-.24 * *$ \\
\hline $\begin{array}{l}\text { Mean discharge } \\
\text { Minimum discharge }\end{array}$ & & & $\begin{array}{l}.31^{* *} \\
.16^{*}\end{array}$ & $.21^{* *}$ & $.16^{* *}$ & $.17 *$ \\
\hline Latitude & & & & $-.24 * *$ & $-.32 * *$ & $-.47 * *$ \\
\hline Longitude & & & $.31^{* *}$ & $-.17^{*}$ & & $-.27 * *$ \\
\hline Standard length & $.39 * *$ & & $.41 * *$ & $.50^{* *}$ & & \\
\hline Sample size & 49 & 48 & 263 & 221 & 296 & 252 \\
\hline$\%$ Variance explained $\left(\mathrm{R}^{2}\right)$ & .56 & .14 & .44 & .43 & .18 & .36 \\
\hline
\end{tabular}

discobolus, because $C$. columbianus is a Columbia drainage equivalent to $C$. discobolus, in size and the number of gill rakers, at least. On the other hand, it is possible to consider these populations of $C$. platyrhynchus as sympatric with a "discobolus-type" species because the interaction between $C$. platyrhynchus and $C$. columbianus could be somewhat comparable to that between $C$. platyrhynchus and $C$. discobolus.

The modal number of gill rakers is higher in $C$. platyrhynchus of the Columbia drainages than elsewhere in its range (Fig. 4). The number of rakers varies from 29-37 (mode $=33$ ) in $C$. platyrhynchus in the Columbia, while $C$. columbianus columbianus has $30-42$ (mode $=34)$ gill rakers in specimens over $70 \mathrm{~mm}$ in standard length. Catostomus columbianus hubbsi, isolated above the Wood River Falls and therefore never in contact with C. platyrhynchus or C. macrocheilus, has 24-31 (mode $=27$ ) gill rakers, and is therefore ecologically and morphologically distinct in a way very suggestive of character displacement.

In C. platyrhynchus from the Columbia basin, the number of gill rakers is negatively correlated with the abundance of $C$. c. columbianus (Table 5) and with gradient. No other environmental variables were significantly correlated.

The number of gill rakers in $C . C . C O-$ lumbianus also varies in the direction predicted by the character displacement hypothesis. In an analysis of all samples of C. c. columbianus the number of gill rakers is higher in the presence of $C$. platyrhynchus and $C$. macrocheilus, in large, stable, high-gradient streams and in the west. Much of this effect is a result of the differentiation of $C$. columbianus hubbsi. With $C$. c. hubbsi removed from the analysis the number of gill rakers in $C$. C. COlumbianus is higher in larger streams, in the south, and in the east-the areas of $C$. platyrhynchus abundance. However, correlations with the competition indices are not significant (Table 5).

\section{Vertebrae}

Correlations between the competition (I) indices and vertebral number indicate significant effects for $C$. discobolus and $C$. platyrhynchus on each other and for $C$. platyrhynchus on $C$. discobolus in the restricted test in the area of sympatry (Table 6). In the Columbia drainage, $C$. platyrhynchus is not affected by C. c. colum- 


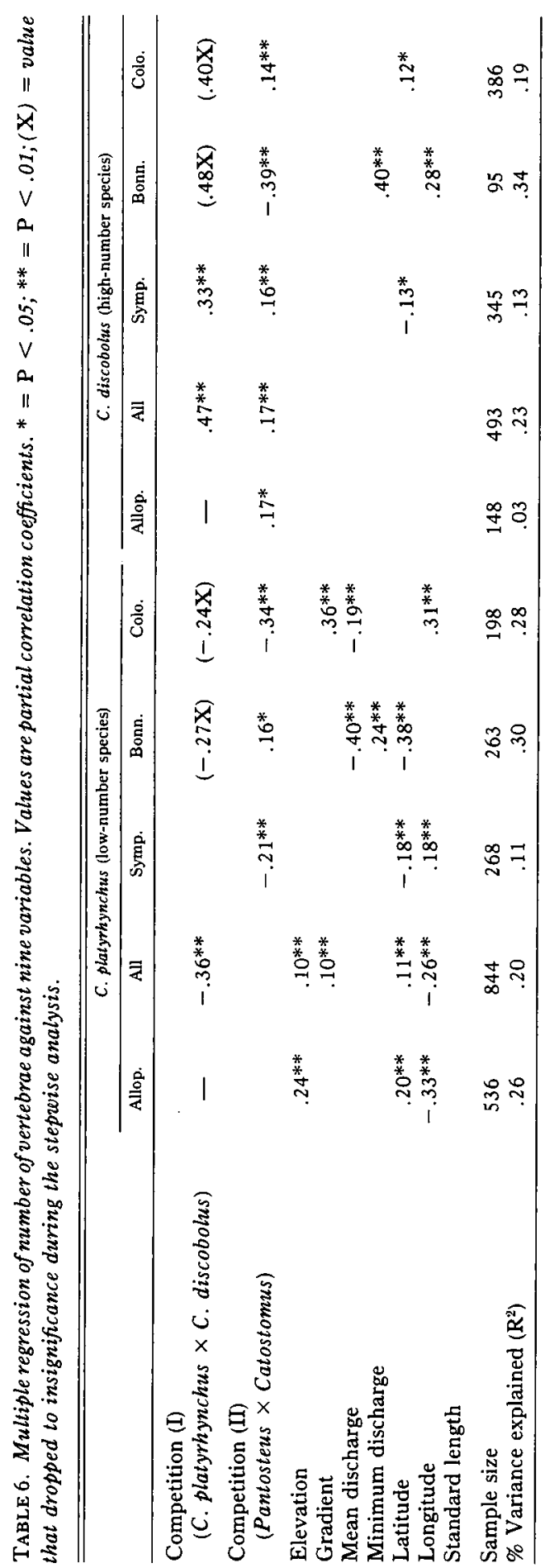

bianus, but $C$. c. columbianus shows an effect if the Wood River populations ( $C$. $c$. hubbsi) are included in the analysis (Table 5). The direction of effects is as predicted by the competition model. These results are similar to those for gill rakers, but not as general, partly because of collinearity among the variables (to be discussed below). Vertebral number is never correlated with length and $\mathrm{R}^{2}$ values are low.

The indices of competition (II) with the subgenus Catostomus are significantly correlated with vertebral number in a number of instances. Vertebral number in C. discobolus is always higher in the presence of $C$. latipinnis, but lower in the Bonneville where it lives with $C$. ardens. C. platyrhynchus, by contrast, has fewer vertebrae in the presence of $C$. latipinnis and more in the presence of $C$. ardens. $C$. latipinnis is a fastwater species in the Colorado drainage and $C$. ardens is a slowerwater species in the Bonneville and upper Snake. Both species have essentially the same vertebral numbers as $C$. discobolus. The interpretation of these results requires evaluation of considerable collinearity among the variables, especially the competition indices, latitude, and longitude. In four of the studies, the competition (I) index was initially the largest, most significant variable in the model, but its partial correlation became insignificant after other variables joined the stepwise selection model. In the Bonneville basin $C$. platyrhynchus began with a partial correlation coefficient of -0.27 , which dropped in response to collinearity with latitude, and $C$. discobolus began with a partial correlation of 0.48 , which dropped to 0.03 because of collinearity with longitude and the competition (II) index. In the Colorado drainage, $C$. platyrhynchus initially showed a partial correlation of -0.24 for the competition (I) index, but the correlation became insignificant because of collinearity with the competition (II) index; $C$. discobolus began the analysis with a value of 0.40 , which dropped from significance when latitude entered the model. Other collinear systems includ- 
ed minimum discharge and the competition (II) index in the analysis of Bonneville C. platyrhynchus. These results are interpreted in the discussion.

Latitude and longitude are important correlates of vertebral number, especially in C. platyrhynchus, which has an extensive distribution. Discharge variables appear to be important especially in C. platyrhynchus and in the Bonneville. Elevation and gradient also seem to be important in $C$. platyrhynchus variation. In that species vertebral number is high in the north and east (Missouri drainage), at high elevations, and in high-gradient streams. In the area of sympatry, however, its vertebral numbers are low in the northeast, as well as being low in the eastern part of the Colorado and the northern part of the Bonneville. Furthermore, its vertebral numbers tend to be lower in the larger streams in the Bonneville and Colorado, as well as in the less permanent streams of the former and the high-gradient streams in the latter drainage. All of these correlations except that with minimum discharge (Table 6) are consistent with expectation of lower vertebral numbers in areas inhabited by $C$. discobolus. In $C$. discobolus, vertebral number seems to be higher in the southern part of the area of sympatry, in the northern part of the Colorado drainage, and in the western part of its Bonneville-Snake range. In the Bonneville it shows a strong tendency toward more vertebrae in more stable streams.

In the Columbia drainage (Table 5) gradient seems to be an important factor in variation of vertebral number (and gill rakers) in C. platyrhynchus. In C. columbianus, competition with $C$. platyrhynchus, elevation, mean discharge and latitude are important overall. But when the analysis is done without the Wood River (C. c. hubbsi) populations, the competition (II) index replaces the competition (I) index, and longitude is added to the other significant variables. In general the trend is toward more vertebrae in larger streams, at lower elevations, and in the south and east, as well as in the presence of $C$. platyrhynchus (and in the absence of $C$. macrocheilus, without C. c. hubbsi in the analysis).

\section{Discussion}

Gill rakers.-The results are interpreted as supporting the hypothesis that feeding competition among these fishes has been sufficient to cause selection for displacement of gill raker number downward in the low-numbered species $(C$. platyrhynchus) and upward in the high-numbered species ( $C$. discobolus) in response to competition with each other, and upward in both species in response to the low-numbered competitors in the subgenus Catostomus. The correctness of this interpretation and its corollaries depends on the statistical reliability of the regression models and the applicability of the hypothesis that gill raker function is related to competition. Several assumptions are discussed in order to evaluate the results and interpretation.

The primary assumptions of this study are that meaningful variables have been chosen for study, that they have been measured accurately and without bias, and that the stepwise regression algorithm correctly selects the functionally important variables from among those sets linked by collinearity. The nonfunctional aspect of latitude and longitude is readily acknowledged. Yet in the absence of methods for measuring trends and spatial autocorrelation in drainage networks, the spatial coordinates are necessary. The competition indices may be the weakest, yet the most important, independent variables. They attempt to estimate immediate as well as long-term competitive effects, yet they must be a compromise, given the absence of data other than that pertaining to samples taken over the past 100 years and distribution maps that summarize the patterns of occurrence. Data on inheritance and rates of selective modification of numbers of gill rakers or vertebrae do not exist, so we can only guess that measurable changes might occur in 50 to 100 generations and that changes of the magnitude seen in our most extreme 
cases might involve much longer times. It seems likely, therefore that combinations of habitat and geographic variables might be better estimators of the density of competitors than our indices. If so, these independent variables would be selected by the model from collinear sets including a competition index. For example, in the analysis of $C$. discobolus in the Bonneville drainage group, the competition (I) index has an initial, significant partial correlation coefficient of 0.27 with number of gill rakers, but is dissolved to insignificance by entry of latitude into the stepwise regression model. It is possible that latitude is simply reflecting the southern areas in which $C$. platyrhynchus are most common in this system (Table 4). Similarly, $C$. platyrhynchus in the Colorado drainage tend to have fewer gill rakers in the south, east, and in stable streams (i.e., $C$. discobolus range). However, in each of these cases other significant variables show effects in the opposite direction to that predicted, and therefore the results are inconclusive. By contrast, $C$. discobolus in the Colorado drainage show increase in gill raker number not only in the presence of $C$. platyrhynchus, but in the habitat situations characteristic of $C$. platyrhynchus: at high elevations, low gradients, and small, stable streams.

The results of the forward, stepwise solutions to the collinear complexes of variables were checked by repeating all analyses using the backward selection procedure. The major conclusions and most of the peripheral interpretations were substantiated: $C$. platyrhynchus showed significant effects overall $(r=$ $-0.31)$ and in the Bonneville $(r=-0.48)$, and $C$. discobolus showed significant effects overall $(r=0.24)$ and in the Colorado $(r=0.21)$.

An additional test of the robustness of the model is available in the comparison of results based on the assumption that $C$. discobolus is allopatric in the upper Colorado drainage. In this comparison, the overall results are the same as shown in Table 4 within one percentage point for each value, except that discharge is a less significant variable. Data for the Colorado drainage and sympatry match less well. In the Colorado the competition (II) index and latitude are significant if $C$. discobol$u s$ is considered to be allopatric. In sympatry, longitude is insignificant. Other values are within 1 to $12 \%$. $\mathrm{R}^{2}$ values are within $3 \%$.

The effect of choosing to analyze the specimens in the size range of $25 \mathrm{~mm}$ to $125 \mathrm{~mm}$ in standard length (the straight line segment of the curve of log number of gill rakers on $\log$ standard length) was checked by repeating the analyses, including all lengths. The general results are the same for $C$. platyrhynchus in that significant competitive effects are shown for the Bonneville drainage and overall. Although the sample sizes are larger, the proportion of the variance explained $\left(\mathbf{R}^{2}\right)$ is smaller by $5-18 \%$. The results for $C$. discobolus differ in that the correlation between number of gill rakers and the competition index is not significant, indicating that in this large species the displacement effect exists only in those individuals that overlap in size with $C$. platyrhynchus. The overall sample size in this case is $449, R^{2}=0.55$, and the significant variables are standard length $0.62 * *$, elevation $0.30^{* *}$, competition index II $0.21^{* *}$, minimum discharge $0.21^{*}$, mean discharge $-0.12^{*}$, and longitude $-0.11^{*}$.

The functional significance of the differences in gill raker number is not yet understood. A difference of one additional raker to 32 (for example) would represent only a proportional change of 0.03 . Assuming spaces of about $0.3 \mathrm{~mm}$ between rakers, the above difference would give a proportional change of about $0.01 \mathrm{~mm}$. Similarly, an increase of one raker per row would increase the number of spaces in the total sieve only from 240 to 248 , for example. It is difficult to imagine significant changes in feeding efficiency based on these values. However, if the changes result from spatial displacement into different habitats, different substrates or different feeding modes, the differences do 
not seem implausible as results of selection. The observed differences, which may be up to three times the values given in the example, might be important in specialized or critical feeding situations. The mechanism still remains to be explained and tested.

Vertebrae.-Results of the analyses of vertebral numbers also support the interpretation that variation has been strongly affected by interactions among competing species. The direction and magnitude of the correlations indicate that, of the variables measured, competition with the most closely related species has had the strongest effect on $C$. platyrhynchus and $C$. discobolus. The effect of $C$. platyrhynchus on C. c. columbianus has been weaker, but significant, in the comparison involving $C$. columbianus hubbsi, which is isolated without catostomid competitors above the falls of the Wood River, Idaho.

In general, these analyses were less stable statistically than those of gill rakers. Collinearity among the variables caused more fluctuation in significance from one step of the analysis to the next. For example, in all four analyses of $C$. platyrhynchus and $C$. discobolus in the Bonneville and Colorado drainages, the competition (I) index entered the stepwise selection model as a dominant, significant variable, and was then eliminated from significance as other variables, especially competition (II), latitude, and longitude entered the model. The methodologically preferred explanation is that the variables remaining have a more proximal causal relationship with variability in vertebral number; however, it is possible that the other variables simply reflect more accurately the likelihood of competition. It would be inappropriate to suggest this explanation, were it not for the weakness of our competition indices and the positive evidence for character displacement. However, even the results that we take as positive evidence for displacement could be an artifact of unmeasured variables that affect both vertebral number and the abundance of competing species. Given these considerations of possible errors in both directions, it can be concluded that the present example provides tentative evidence for the occurrence of character displacement in vertebral numbers.

The weakest link in the explanation of displacement in vertebral number is the absence of a convincing model for a functional relationship between competition and vertebral number. We chose this variable with the expectation that it would provide a contrasting (relative to gill rakers) test of the null hypothesis that character displacement might be an artifact of responses to other environmental variables (Grant, 1972). Surprisingly, it shows displacement; therefore it requires a functional explanation. We suggest that the effect results from competitive displacement of individuals into different habitat gradients with respect to discharge, current, and temperature, and that strength and flexibility, which depend on optimal segmental proportions of vertebrae and muscle units relative to fish size, are also changed. The effect is therefore suggested to be secondary to a habitat displacement.

Despite the lack of functional explanations linking the observed displacement to competition and selection, the attempt to test the evidence by stepwise multiple linear regression appears to be useful. The partition of variance into proportions explainable by different environmental variables provides insight into the sources of geographic variations. An interesting proportion of the total variance was accounted for in most models and all independent variables were significantly associated with at least some variation in number of gill rakers and vertebrae. In seven of eight independent tests (the models examining an entire group-"all" rather than a subset-Table 4-6), the index (I) for competition between closest relatives is signifcant. Among all analyses reported in Tables 4-6, the index (I) for competition among Pantosteus was significant in 11 of 22 possible models and has the highest partial correlation among the environmental variables in five models. The index (II) for competition between species in different subgenera is significant in 14 of 26 
models. The frequency of significance of the other environmental variables is as follows: elevation $10 / 26$, gradient $9 / 26$, mean discharge $8 / 26$, minimum discharge $6 / 26$, latitude $13 / 26$, and longitude $11 / 26$.

Use of allopatric populations as "control" models in the analyses provided additional evidence that significance of the competition indices was not due to collinearity with other environmental variables. Attempts to analyze sympatric populations alone as "controlled" tests of collinearity were only partially successful; significance of the competition (I) index was substantiated in only two of four cases.

Other recent studies purporting to demonstrate character displacement generally lack quantified comparison of variation within areas of allopatry and sympatry, and thus fail to provide a comparative basis for understanding causes of differences between these groups of populations. Schindel and Gould (1977) provide a univariate and multivariate comparison of shell form in fossil Bermudian land snails, Poecilozonites circumfirmatus and $P$. discrepans. Four different lithologies of preservational environment are interpreted as different living environments. Species differences are found to conform to categories of sympatry and allopatry, not to lithology; sympatric forms differ most and seem to vary in parallel across lithologies. The demonstration is plausible to the extent that variation is compared in relation to one environmental variable and is graphically presented to enable comparison within as well as between allopatry and sympatry. The authors argue that the fossil record is superior to the Recent time slice for demonstrating patterns of variation among populations, but since they fail to sequence their samples chronologically, their time slice is merely thicker, not more informative. A more convincing example of morphological character displacement in the fossil record is offered by Kellog (1975). This example involves the radiolarian species Eucyrtidium matuyamai and $E$. calvertense from a pair of North Pacific deep sea cores of
Miocene to Recent age. Following the establishment of sympatry $E$. calvertense underwent a marked decrease in size as $C$. matuyamai from both allopatric and sympatric populations increased in size. Further, $E$. calvertense exhibited no significant size changes either prior to the establishment of sympatry or after the extinction of $E$. matuyamai in these cores. Although size variation due to environmental causes cannot be ruled out, these data are consistent with an hypothesis of character displacement and are perhaps, the best available form the fossil record.

Berry (1975) has argued that reduction in specialization for molluscivory (measured by head width-carapace length regressions) in the musk turtle (Sternotherus minor) when in sympatry with a congener ( $S$. odoratus) represents a case of convergent character displacement. The argument is not convincing because variation in trophic morphology attributable to variation in food resource abundance is not quantified. Variation in the density of the specialist's principal prey (Goniobasis; Berry, 1975) is sufficient to account for the observed differences in regression models without recourse to a competitive explanation. The same considerations complicate the interpretation of dietary differences between allopatric and sympatric populations of the insectivorous bats Myotis evotis and $M$. auriculus (Husar, 1976) as an example of behavioral character displacement. Likewise, the example of character displacement in the sympatric skates Raja erinacea and $R$. ocellata offered by McEachran and Martin (1976) must be interpreted with extreme caution.

Huey and Pianka (1974) and Huey et al. (1974) reported a case of probable divergent character displacement involving two species of legless fossorial skinks (Typhlosaums) from the southern Kalahari desert. Snout-vent lengths, head dimensions, proportional head lengths, and prey size of the larger species ( $T$. lineatus) are larger in sympatry than in allopatry. The geographic range of the smaller species $(T$. gariepensis) is entirely included within 
that of $T$. lineatus. Typhlosaurus gariepensis is restricted to southern sandridge habitats.

The interpretation that this represents a case of divergent character displacement is weakened by two considerations. First, the attempt to quantify possible clinal variation in the characters of interest is weak. The comparison was carried out on data pooled from several geographic locations representing different classes of allopatry and sympatry. Thus the analysis of geographic variation in allopatry as suggested by Grant (1972) cannot be done. The ranges of allopatric populations studied average $2^{\circ} \mathrm{E}$ of the sympatric populations further emphasizing the need for quantifying geographic variation in allopatry and sympatry separately (Grant, 1972). Pianka et al. (1978) attempted to separate physical environmental from competitive influences on body size by comparing body sizes of $T$. lineatus from allopatric northern sandridge and flatland localities. Lack of significant differences in body size in this comparison indicated that the presence of the sandridge microhabitat had effect on body size in $T$. $l i$ neatus. However, a contrast involving allopatric northern and southern flatland populations revealed that $T$. lineatus from northern flatland localities are significantly larger than are those from southern flatland localities. Second, the two species differ significantly in microhabitat associations (Huey et al., 1974). It is possible that the effects attributed to competitive character displacement may be due to differences in character, availability, and (or) utilization of microhabitats among allopatric and sympatric populations of $T$. $l i$ neatus independent of any interaction with $T$. gariepensis.

Fenchel (1975) presented a case for competitive character displacement in populations of mud snails from northern Jutland. Hydrobia ventrosa was smaller in average body size when in sympatry with $H$. ulvae than when allopatric. The latter species showed the reverse size trend. The author points out that a number of environmental factors can influence body size in snails and demonstrates different salinity preferences in these two species (Fenchel, 1975). However, since no attempt was made to quantify the possible effects of such factors on body size, the competitive interpretation is weakened by the existence of a likely but untested alternative. Fenchel and Kofoed (1976) subsequently demonstrated exploitative interspecific competition between these two species in a series of laboratory experiments. They also showed that differences in body size are related to the size of the substrate filtered by these snails while feeding. These results suggest that the earlier competitive character displacement explanation for the differences in body size in sympatry may be correct.

Character displacement should be as widespread as the above examples indicate, yet most demonstrations go no further than showing consistency with the explanation and are therefore equivocal. The mechanisms, though predictable in general, are not understood. Quantitative comparison of the effect of competition in relation to other causes of geographic variation should provide the background for development of functional models of competitive character displacement.

\section{SUMMARY}

The study of competitive character displacement requires examination of geographic variation in relation to distribution of competitors as well as other sources of selection. Stepwise multiple linear regression is a technique for partitioning variation into separate patterns of correlation associated with several geographic and environmental variables. In this study, variation in three species of mountain suckers was compared in relation to potential competition with each other and with other species in the same genus, as well as to latitude, longitude, elevation, stream gradient, maximum discharge and minimum discharge. The index representing potential competition with the closest relative is significantly correlated with variation in the numbers of gill rakers and vertebrae in Catostomus platyrhynchus 
and $C$. discobolus. The index of potential competition with other Catostomus is frequently correlated with variation, as are the geographic coordinates and environmental variables. Stepwise selection of independent variables allows assignment of partial correlations to collinear variables and thus allows tests of alternative hypotheses. Competition appears to be a dominant cause of geographic variation in the characters examined.

The significant examples of displacement in both characters are divergent. In C. discobolus (the species with high numbers) displacement of gill raker number was upward in response to all competitors. In $C$. platyrhynchus the number of gill rakers is negatively correlated with the index of interaction with $C$. discobolus but increases in response to presence of lower-numbered species of Catostomus. Variation in vertebral numbers follows the same pattern in the interaction between C. platyrhynchus and $C$. discobolus but is more complicated in relation to other Catostomus, which have vertebral numbers similar to $C$. discobolus.

Interaction between $C$. platyrhynchus and $C$. columbianus, the Columbia drainage analogue of $C$. discobolus, results in upward displacement of gill rakers and vertebrae in $C$. columbianus and downward displacement of gill rakers in C. platyrhynchus. The result observed in $C$. columbianus is based primarily on the contrast with allopatric $C$. columbianus hubbsi, which has low numbers. In response to $C$. macrocheilus, which has few gill rakers and high vertebral numbers, $C$. columbianus shows upward displacement of gill rakers and fewer vertebrae.

Analysis of interaction among different size classes reveals that the observed displacement of numbers of gill rakers in $C$. discobolus is limited to individuals in the size classes that overlap with $C$. platyrhynchus. Above that size, the number does not increase with growth. The competitive effect on gill raker number is thus restricted to interactions that occur in the first months of growth and probably involves the effect of gill raker number and spacing on feeding efficiency. The displacement of vertebral number is probably related to interactions among habitat, body size, and swimming mechanics.

\section{ACKNOWLEDGMENTS}

We are indebted to Drs. Peter R. Grant, Raymond B. Huey, and J. R. Nursall for helpful reviews of earlier drafts of this paper. The technical assistance provided by Mark Orsen, Krystyna Swirydczuk, and Marsha Dunham is gratefully acknowledged.

\section{Literature Cited}

Barlow, G. W. 1961. Causes and significance of morphological variation in fishes. Syst. Zool. 10:105-117.

BERRY, J. F. 1975. The population effects of ecological sympatry on musk turtles in northern Florida. Copeia 1975:692-701.

Brown, W. L., AND E. O. WILSON. 1956. Character displacement. Syst. Zool. 5:49-64.

Cody, M. L. 1974. Competition and the structure of bird communities. Monogr. Pop. Biol. No. 7 . Princeton Univ. Press.

Draper, N. R., AND H. Smith. 1966. Applied Regression Analysis. John Wiley and Sons, Inc., N.Y.

Fenchel, T. 1975. Character displacement and coexistence in mud snails (Hydrobiidae). Oecologica 20:19-32.

Fenchel, T., AND L. H. Kofoed. 1976. Evidence for exploitative interspecific competition in mud snails (Hydrobiidae). Oikos 27:367-376.

Fowler, J. A. 1970. Control of vertebral number in teleosts-an embryological problem. Quart. Rev. Biol. 45:148-167.

Gosline, W. A. 1971. Functional Morphology and Classification of Teleostean Fishes. Univ. Hawaii Press.

Grant, P. R. 1972. Convergent and divergent character displacement. Biol. J. Linn. Soc. 4:3968.

. 1975. The classical case of character displacement. Evol. Biol. 8:237-337.

HuBBS, C. L. 1926. Variations in the number of vertebrae and other meristic characters of fishes correlated with the temperature of water during development. Amer. Natur. 56:360-372.

Huey, R. B., AND E. R. Pianka. 1974. Ecological character displacement in a lizard. Amer. Zool. 14:1127-1136.

Huey, R. B., E. R. Pianka, M. E. Egan, AND L. W. Coons. 1974. Ecological shifts in sympatry: Kalahari fossorial lizards (Typhlosaurus). Ecology 55:304-316.

HuSAR, S. L. 1976. Behavioral character displacement: evidence of food partitioning in insectivorous bats. J. Mamm. 57:331-338. 
KELLOG, D. E. 1975. Character displacement in the Radiolarian genus Eucyrtidium. Evolution 29:736-749.

LindSEY, C. C. 1975. Pleomerism, the widespread tendency among related fish species for vertebral number to be correlated with maximum body length. J. Fish. Res. Bd. Canada 32:2453-2469.

MACARThuR, R. H. 1972. Geographical Ecology. Harper and Row, N.Y.

MacArthur, R. H., AND R. Levins. 1964. Competition, habitat selection, and character displacement in a patchy environment. Proc. Nat. Acad. Sci. USA 51:1207-1210.

. 1967. The limiting similarity, convergence and divergence of coexisting species. Amer. Natur. 101:377-385.

MacArthur, R. H., AND E. O. Wilson. 1967. The theory of island biogeography. Monogr. Pop. Biol. No. 1. Princeton Univ. Press.

McEachran, J. D., and C. O. Martin. 1977. Possible occurrence of character displacement in sympatric skates Raja erinacea and $R$. ocellata (Pisces: Rejidae). Env. Biol. Fish. 2:121-130.

NuRSall, J. R. 1974. Character displacement and fish behavior, especially in coral reef communities. Amer. Zool. 14:1099-1118.

Pianka, E. R., R. B. Huey, and L. R. Lawlor. 1978. Niche segregation in desert lizards. In $\mathrm{D}$. J. Horn, R. Mitchell, and G. R. Stairs (eds.), Analysis of Ecological Systems. Ohio State Univ. Press, Columbus.

Rivas, L. R. 1964. A reinterpretation of the terms "sympatric" and "allopatric" with proposal of the additional terms "syntopic" and "allotopic." Syst. Zool. 13:42-43.

Schindel, D. E., AND S. J. GouLd, 1977. Biological interaction between fossil species: character displacement in Bermudian land snails. Paleobiology 3:259-269.

SChOENER, T. W. 1969a. Models of optimal size for solitary predators. Amer. Natur. 103:277313.

- 1969b. Optimal size and specialization in constant and fluctuating environments: an energy-time approach. Brookhaven Symp. Biol. 22:103-114.

1970. Size patterns in West Indian Anolis lizards. П. Correlations with sizes of particular sympatric species-displacement and convergence. Amer. Natur. 104:155-174.

- 1974. Resource partitioning in ecological communities. Science 185:27-39.

1975. Presence and absence of habitat shift in some widespread lizard species. Ecol. Monogr. 45:233-258.

SMITH, G. R. 1966. Distribution and evolution of the North American catostomid fishes of the subgenus Pantosteus, genus Catostomus. Misc. Publ. Mus. Zool., Univ. Michigan 129:1-132.

1978. Biogeography of intermountain fishes. In K. Harper et al. (eds.), Intermountain Biogeography. Great Basin Naturalist Memoirs $2: 17-42$.

TÅNING, A. V. 1952. Experimental study of meristic characters in fishes. Biol. Rev. Cambridge Phil. Soc. 27:169-193. 